\title{
Myeloperoxidase in Chronic Kidney Disease
}

\author{
A. Madhusudhana Rao $\cdot$ Usha Anand · \\ C. V. Anand
}

Received: 25 March 2010/Accepted: 10 June 2010/Published online: 14 September 2010

(C) Association of Clinical Biochemists of India 2010

\begin{abstract}
Numerous lines of evidence implicate a role of myeloperoxidase (MPO) in the pathogenesis of cardiovascular disease (CVD). It is a well accepted fact that patients with chronic kidney disease (CKD) are at an increased risk for CVD. MPO is a pro-oxidant enzyme which could be involved in the increased susceptibility of these patients to CVD. Hence, the levels of plasma MPO was determined in healthy controls as well as in patients with CKD [stratified with the level of their kidney failure as CKD stages II-V (end stage renal disease)]. Plasma MPO was assayed by a spectrophotometric method. Serum urea and creatinine were estimated on a clinical chemistry analyzer using standard laboratory procedures. The mean plasma MPO levels were significantly lower with advancing stages of renal failure $(P<0.001)$. There was a positive correlation between MPO and GFR $(r=+0.89$, $P<0.001)$ and a negative correlation with urea $(r=$ $-0.85, P<0.001)$ and creatinine $(r=-0.82, P<0.001)$. While an inverse association was observed between plasma MPO and urea in CKD patients, such an association was not observed in control subjects $(P=0.43)$. In conclusion, the decline in plasma MPO levels may be due to the inhibitory effect of uraemic toxins on the enzyme.
\end{abstract}

Keywords Chronic kidney disease $\cdot$ MPO-hydrogen peroxide-chloride system - Oxidative stress - Uraemic toxins - Cardiovascular disease

A. Madhusudhana Rao · U. Anand · C. V. Anand ( $\square)$ Department of Biochemistry, PSG Institute of Medical Sciences and Research, Coimbatore 641004, Tamil Nadu, India e-mail: anandvasudevarao@gmail.com;

anand_vasudevarao@yahoo.com

\section{Introduction}

Myeloperoxidase (MPO) was traditionally considered to be a bactericidal agent [1]. Recent investigations revealed a crucial role of MPO in chronic, nonmicrobial inflammatory processes such as neurodegenerative diseases and atherosclerosis [2]. MPO, a glycosylated, arginine-rich, extremely basic protein (isoelectric point $>10$ ) [1] is comprised of two subunits, encoded within a single mRNA. Two of each subunits are assembled with heme molecules to produce the functional enzyme (donor: hydrogen peroxide, oxidoreductase, EC 1.11.1.7). MPO is stored in primary azurophilic granules of leukocytes and the enzyme accounts for up to 5 and $1 \%$ of total cell protein content, in neutrophilic polymorphonuclear leukocytes (neutrophils) and monocytes, respectively [3].

The ability of MPO to generate hypochlorous acid/ hypochlorite $\left(\mathrm{HOCl} / \mathrm{OCl}^{-}\right)$from hydrogen peroxide in the presence of chloride ions is a unique and defining activity for this enzyme [4]. The importance of MPO-catalyzed oxidative reactions and formation of a variety of chlorinated protein and lipid adducts (with hypochlorous acid as the major oxidant in causing tissue injury by phagocytic cells) has been emphasized [5]. Furthermore, high levels of MPO-mediated endothelial dysfunction may be an important mechanistic link between oxidation, inflammation, and cardiovascular disease (CVD) [6]. An elevated level of plasma MPO served as independent predictor of increased risk of myocardial infarction [7]. However, the role of MPO in chronic kidney disease (CKD) is poorly understood, and not much data is available regarding the variations of this enzyme in these patients. Hence, the present study was undertaken to evaluate the MPO levels in various stages of CKD including end stage renal disease (ESRD). It was speculated that raised levels of this 
enzyme might be one of the factors responsible for the increased risk that these patients have for developing CVD.

\section{Materials and Methods}

\section{Subjects}

The study was conducted on successive patients after informed consent was obtained from them. It was approved by the Institutional Human Ethics Committee. A total of 100 subjects (73 male and 27 female, aged 19-76 years) were recruited for this study. Control subjects $(n=20)$ with normal kidney function had GFR $>90 \mathrm{ml} / \mathrm{min} / 1.73 \mathrm{~m}^{2}$, while CKD patients with stage II $(n=20)$ had GFR between 60 and $89 \mathrm{ml} / \mathrm{min} / 1.73 \mathrm{~m}^{2}$, stage III $(n=20)$ had GFR between 30 and $59 \mathrm{ml} / \mathrm{min} / 1.73 \mathrm{~m}^{2}$, stage IV had GFR between 15 and $29 \mathrm{ml} / \mathrm{min} / 1.73 \mathrm{~m}^{2}$ and stage V (ESRD) had GFR $<15 \mathrm{ml} / \mathrm{min} / 1.73 \mathrm{~m}^{2}$ [8]. Patients suffering from diabetes mellitus, diabetic nephropathy, and acute infections were excluded from the study.

\section{Methodology}

Samples of blood were collected from the patients using vacutainers (BD, USA) containing clot activator for serum and with fluoride-EDTA for plasma. The samples were centrifuged for $15 \mathrm{~min}$ at $2000 \mathrm{rpm}$ and stored at $-20^{\circ} \mathrm{C}$ until analysis. Serum creatinine was measured using an automated Jaffe's assay on the Olympus AU 400 (Olympus Optical, Tokyo, Japan) analyzer according to the manufacturer's procedure. Serum urea was estimated using standard clinical chemistry procedure with Cobas Integra 400 plus auto analyzer, using Roche reagents.

GFR was calculated using the re-expressed four variable MDRD formula [9].

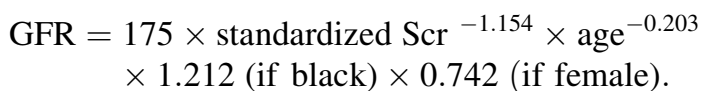

\section{Estimation of Plasma MPO}

MPO activity was measured spectrophotometrically using $o$-dianisidine (Sigma-Aldrich) and hydrogen peroxide [10]. In the presence of $\mathrm{H}_{2} \mathrm{O}_{2}$ as oxidizing agent, MPO catalyses the oxidation of $o$-dianisidine yielding a brown coloured product, oxidized $o$-dianisidine, with a maximum absorbance at $470 \mathrm{~nm}$, according to the following overall reaction:

$2 \mathrm{H}_{2} \mathrm{O}_{2}+o$-dianisidine $\rightarrow$ oxidized dianisidine $+4 \mathrm{H}_{2} \mathrm{O}$.

One unit (U) of MPO activity was defined as that degrading $1 \mu \mathrm{mol}$ of hydrogen peroxide per minute at $25^{\circ} \mathrm{C}$.

Statistical Analysis

All the values obtained are expressed as mean and SD. Student's $t$ test was applied to assess the significance. Pearson's correlation coefficient was used to assess the association between the parameters. A $P$ value $<0.05$ was considered to be significant.

\section{Results}

The results are shown in Tables 1, 2 and Figs. 1, 2a, b, 3a, b. Table 1 shows mean and standard deviation of age, male to female ratio, GFR, urea and creatinine of controls and CKD patients.

The serum creatinine, urea levels in the control samples varied from 0.58 to $0.81,17$ to $47 \mathrm{mg} / \mathrm{dl}$ and for the CKD patients it varied from 0.73 to $10.25,17$ to $134 \mathrm{mg} / \mathrm{dl}$. The MPO levels in controls varied from 136.80 to $290.70 \mathrm{U} / 1$ and for the CKD patients it varied from 11.97 to $107.73 \mathrm{U} / \mathrm{l}$.

The plasma MPO levels were significantly lower in CKD when compared with the controls $(P<0.05)$. When the patients were segregated on the basis of the stages of CKD, plasma MPO levels were found to fall steadily with advancing renal failure. Also, statistically significant

Table 1 Age, sex, GFR and biochemical parameters in predialysis patients at various stages of CKD

\begin{tabular}{lccccc}
\hline & Controls $(n=20)$ & Stage II $(n=20)$ & Stage III $(n=20)$ & Stage IV $(n=20)$ & Stage V $(n=20)$ \\
\hline Age (years) & $35 \pm 5.4$ & $40 \pm 12.3$ & $43 \pm 12.7$ & $52 \pm 13.2$ & $59 \pm 11.4$ \\
Sex (male/female) & $14 / 6$ & $16 / 4$ & $11 / 9$ & $14 / 6$ & $18 / 2$ \\
GFR (ml/min/1.73 m m $\left.^{2}\right)$ & $113 \pm 8.6$ & $71 \pm 8.8^{*}$ & $38 \pm 6.3^{*}$ & $18 \pm 3.1^{*}$ & $11 \pm 2.4^{*}$ \\
S. urea (mg/dl) & $25 \pm 5.3$ & $33 \pm 8.8^{* *}$ & $48 \pm 14.5^{* *}$ & $71 \pm 15.3^{*}$ & $111 \pm 16.5^{*}$ \\
S. creatinine (mg/dl) & $0.73 \pm 0.07$ & $0.95 \pm 0.12^{*}$ & $1.74 \pm 0.29^{*}$ & $3.27 \pm 0.58^{*}$ & $6.77 \pm 1.82^{*}$ \\
Plasma MPO(U/l) & $217 \pm 31.6$ & $100 \pm 5.6^{*}$ & $73 \pm 9.1^{*}$ & $44 \pm 8.8^{*}$ & $21 \pm 6.16^{*}$ \\
\hline
\end{tabular}

Values are Mean $\pm \mathrm{SD} ; * P<0.001$ and $* * P<0.01$ (compared to controls) 
Table 2 Regression analyses between plasma MPO levels and GFR, urea, creatinine values in CKD patients

\begin{tabular}{llcc}
\hline S. no. & & $r$ Value & $P$ value \\
\hline 1 & Plasma MPO and GFR & +0.89 & $<0.001$ \\
2 & Plasma MPO and urea & -0.85 & $<0.001$ \\
3 & Plasma MPO and SCr & -0.82 & $<0.001$ \\
\hline
\end{tabular}

The correlation coefficients $(r)$ were significant at the indicated $P$ value

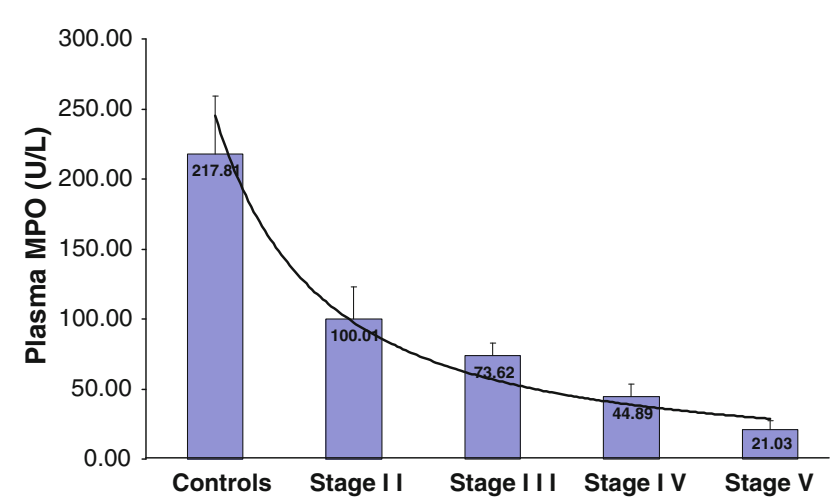

Fig. 1 Histogram showing the plasma MPO levels (U/l) in CKD patients stratified with the level of their kidney failure in CKD stages II-V (ESRD)
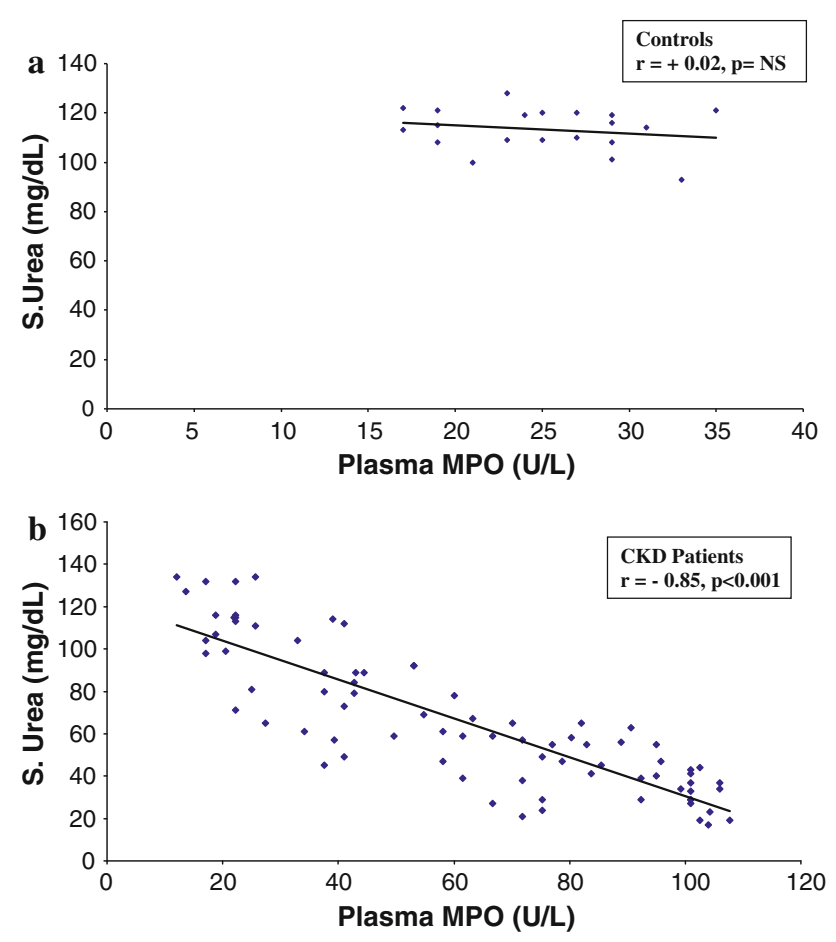

Fig. 2 Regression analysis showing the relationship between plasma MPO and serum urea, in controls (a) and CKD patients (b)
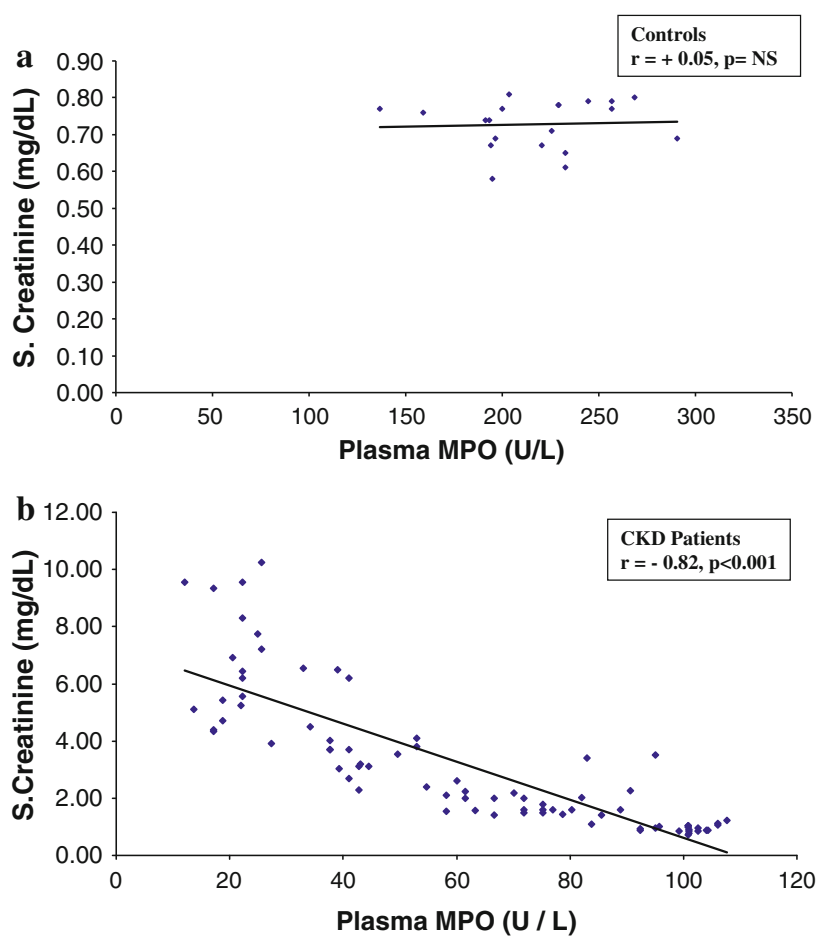

Fig. 3 Regression analysis showing the relationship between plasma MPO and serum creatinine, in controls (a) and CKD patients (b)

differences were found between each stage and its preceding one as indicated in the graph (Fig. 1).

There was a positive correlation between plasma MPO and GFR $(r=+0.89, P<0.001)$ and a negative correlation was observed between plasma MPO and $\mathrm{SCr}(r=-$ $0.82, P<0.001$, Table 2). There was a significant negative correlation between plasma MPO and urea, in CKD patients $(r=-0.85, P<0.001$, Fig. $2 b)$; while there was no significant correlation in control subjects (Fig. 2a). Similarly a significant negative correlation was observed between plasma MPO and S. creatinine in CKD patients (Fig 3b), while no such correlation was observed between these two parameters in the controls (Fig 3a).

\section{Discussion}

To the best of our knowledge this is the first study which has demonstrated that there is a progressive fall in mean plasma MPO levels with advancing renal disease. MPO is an enzyme which has been shown to play an important role in the initiation and progression of atherosclerosis. Several mechanisms by which elevated levels of MPO can promote cardiovascular complications have been described [11]. Patients with CKD are at a higher risk for CVD [12]. Therefore this study was performed to determine MPO activity in patients with CKD. However, results have shown that plasma MPO levels are significantly lower in CKD 
patients as compared to controls. Thus there is a clear indication that this enzyme does not have a role in the etiology of cardiovascular complications in patients with CKD.

Several studies have indicated that MPO serves as an enzymatic source for bioactive lipids and its generated adduct products have been shown to adversely affect the protective capacity of high-density lipoprotein as well as to induce endothelial dysfunction [13, 14]. Inflammation and oxidative stress are known to induce endothelial dysfunction and the role of MPO remains controversial in these patients. This study has demonstrated that in patients with CKD the enzyme MPO does not have a significant role in oxidative stress mediated endothelial dysfunction. Capeillere et al. [15] have also suggested that in uraemic patients, plasma proteins could be directly oxidized by an MPO independent mechanism and the generation of advanced oxidation protein products occurs mainly via an MPO independent pathway. These observations emphasize the role of other agents in causing increased oxidative stress-mediated endothelial dysfunction, which might ultimately manifest in higher incidence of cardiovascular complications in CKD.

The reasons for the fall in the levels of plasma MPO are not known with certainty. However, it could be speculated that this may be due to the uremic environment. Cyanate $\left(\mathrm{CNO}^{-}\right)$is chemically similar to thiocyanate $\left(\mathrm{SCN}^{-}\right)$, a so-called pseudohalide, which can serve as substrate for peroxidases such as lactoperoxidase, MPO and eosinophil peroxidase yielding hypothiocyanous acid (HOSCN) [16]. Dirnhuber and Schutz [17] reported that under physiological conditions, cyanate $\left(\mathrm{CNO}^{-}\right)$forms spontaneously in solutions containing urea, and is present in urine and the body fluids of uraemic patients and reaches equilibrium in the molar ratio of approximately 0.0075:1 $\left(\mathrm{CNO}^{-}\right.$-urea). Therefore it is possible that $\mathrm{CNO}^{-}$also may act as a pseudohalide but that the product of an MPO$\mathrm{CNO}^{-}$reaction, if any, could be relatively impotent in bacterial killing and/ or may directly inhibit MPO [18]. The present study has also shown a significant negative correlation between urea and MPO in CKD; while no significant correlation was observed in the control subjects. Hence, it could be speculated that the decline in MPO levels in CKD patients might be due to the inhibitory action of uraemic toxins, particularly $\mathrm{CNO}^{-}$, on this enzyme.

In conclusion, the study has shown that, plasma MPO levels decline steadily as the CKD progresses, possibly due to the inhibitory effect of uraemic toxins on the enzyme. However, the precise inhibitory role of uraemic toxins such as cyanate $\left(\mathrm{CNO}^{-}\right)$on MPO has to be investigated in detail. This study further demonstrates that the enzyme
MPO cannot be invoked to account for the increased susceptibility to CVD of CKD patients.

\section{References}

1. Hampton MB, Kettle AJ, Winterbourn CC. Inside the neutrophil phagosome: oxidants, myeloperoxidase, and bacterial killing. Blood. 1998;92:3007-17.

2. Podrez EA, Abu-soud HM, Hazen SL. Myeloperoxidase generated oxidants and atherosclerosis. Free Radic Biol Med. 2000;28: 1717-25.

3. Brown KE, Brunt EM, Heinecke JW. Immunohistochemical detection of myeloperoxidase and its oxidation products in $\mathrm{Ku}-$ pffer cells of human liver. Am J Pathol. 2001;159:2081-8.

4. Winterbourn CC, Kettle AJ. Biomarkers of myeloperoxidase derived hypo chlorous acid. Free Radic Biol Med. 2000;29: 403-9.

5. Heinecke JW. Mechanisms of oxidative damage by myeloperoxidase in atherosclerosis and other inflammatory disorders. J Lab Clin Med. 1999;133:321-5.

6. Vita JA, Brennan ML, Gokce N, Mann SA, Goormastic M, Shishehbor MH, et al. Serum myeloperoxidase levels independently predict endothelial dysfunction in humans. Circulation. 2004;110:1134-9.

7. Brennan ML, Penn MS, Vn Lente FV, Nambi V, Shishehbor MH, Aviles RJ. Prognostic value of myeloperoxidase in patients with chest pain. N Engl J Med. 2003;349:1595-604.

8. Levey AS, Coresh J, Balk E, Kausz AT, Levin A, Steffes MW, et al. National Kidney Foundation practice guidelines for chronic kidney disease: evaluation, classification, and stratification. Ann Intern Med. 2003;139:137-47.

9. Levey AS, Coresh J, Greene T et al. Expressing the MDRD study equation for estimating GFR with IDMS traceable (gold standard) serum creatinine values. J Am Soc Nephrol 2005;16:69A.

10. Krueger AJ, Yang JJ, Roy TA, Robbins DJ, Mackerer CR. An automated myeloperoxidase assay. Clin Chem. 1990;36:158.

11. Arsenault BJ, Stroes ES, Boekholdt SM. Is myeloperoxidase a useful marker to predict the risk of cardiovascular events? Curr Cardiovasc Risk Rep. 2009;3:137-43.

12. Weiner DE, Tighiourat H, Amin MG, Stark PC, Macleod B, Griffith JL, et al. Chronic kidney disease as a risk factor for cardiovascular disease and all-cause mortality: a pooled analysis of community-based studies. J Am Soc Nephrol. 2004;15:1307-15.

13. Malle E, Buch T, Grone HJ. Myeloperoxidase in kidney disease. Kidney Int. 2003;64:1956-67.

14. Maruyama Y, Lindholm B, Stenvinkel P. Inflammation and oxidative stress in ESRD - the role of myeloperoxidase. J Nephrol. 2004;17(Suppl 8):72-6.

15. Capeillere BC, Gausson V, Nguyen AT, Descamps LB, Drueke T, Witko SV. Respective role of uraemic toxins and myeloperoxidase in the uraemic state. Nephrol Dial Transplant. 2006;21: 1555-63.

16. Slungaard A, Mahoney JR. Thiocyanate is the major substrate for eosinophil peroxidase in physiologic fluids. J Biol Chem. 1991; 266:4903-10.

17. Dirnhuber P, Schutz F. The isomeric transformation of urea into ammonium cyanate in aqueous solutions. Biochem J. 1948;42: 628-32.

18. Mingwei Q, John WE, Simon PW. Cyanate-mediated inhibition of neutrophil myeloperoxidase activity. Biochem J. 1997;326: $159-66$. 